\title{
As tecnologias não são neutras: por uma tecnologia participativa e emancipadora
}

\author{
Entrevista com Wagner Ragi Curi Filho sobre a criação da Associação Brasileira de \\ Ensino, Pesquisa e Extensão em Tecnologias Sociais - ABEPETS ${ }^{1}$
}

Júlia Granja F. Pereira ${ }^{2}$

Robson Pereira de Lima $^{3}$

Sérgio Luiz Gusmão Gimenes Romero ${ }^{4}$

Wagner Ragi Curi Filho é doutor em Administração de Empresas pela Fundação Getúlio Vargas - FGV/SP. Possui graduação e mestrado em Engenharia de Produção pela Universidade Federal de Minas Gerais - UFMG. É professor, pesquisador e, atualmente, coordenador do curso de Engenharia de Produção da Universidade Federal de Ouro Preto UFOP, Campus de João Monlevade/MG. Tem experiência na área de Engenharia de Produção, atuando em temas variados, tais como: índices de desempenho, competências e gestão de serviços; organização do trabalho; economia solidária; tecnologia social; autogestão nas relações de trabalho; e avaliação dos impactos sociais de universidades. $\mathrm{O}$ pesquisador integra, ainda, o grupo responsável pela proposta de construção, em âmbito nacional, de uma organização de pesquisa, ensino e extensão com foco em Tecnologia Social. E-mail: wagner@ufop.edu.br.

\footnotetext{
${ }^{1} \mathrm{~A}$ entrevista foi realizada por videoconferência no dia 7 de junho de 2021, sendo posteriormente transcrita. ${ }^{2}$ Graduanda em Engenharia de Minas pela Universidade do Estado de Minas Gerais - UEMG, Unidade João Monlevade, MG, Brasil. E-mail: julia.0693338@discente.uemg.br.

${ }^{3}$ Graduado em Ciências Econômicas pela Universidade Federal Fluminense - UFF. Mestre e também Doutor pelo Programa de Engenharia de Produção - PEP da Universidade Federal do Rio de Janeiro -UFRJ, com ênfase em Gestão e Inovação. É professor e pesquisador da Universidade do Estado de Minas Gerais - UEMG, Unidade de João Monlevade, MG, Brasil. E-mail: robsonpep@gmail.com.

${ }^{4}$ Graduado em Letras e Mestre em Estudos Literários pela Faculdade de Ciências e Letras da UNESP, Campus Araraquara. Doutorando em Letras pela Universidade Federal de Minas Gerais - UFMG. É professor e pesquisador da Universidade do Estado de Minas Gerais - UEMG, Unidade João Monlevade, MG, Brasil. Email: sergio.romero@uemg.br.
} 


\section{Como e por que surgiu a iniciativa de criação da Associação Brasileira de Ensino, Pesquisa e Extensão em Tecnologias Sociais - ABEPETS?}

Embora seja uma ideia antiga, alimentada por diferentes pessoas que trabalham com tecnologia social, a iniciativa foi impulsionada pela publicação de um edital do Conselho Nacional de Desenvolvimento Científico e Tecnológico - CNPQ em $2018^{5}$. A partir desse edital, tanto coordenadores quanto outros pesquisadores que não estavam com projetos dedicados à tecnologia social aprovados no CNPQ começaram a se reunir para debater assuntos relacionados à temática, assim como deliberar sobre a própria chamada do Conselho Nacional de Desenvolvimento Científico e Tecnológico e também sobre próximos editais.

A partir desse debate mais amplo acerca da Tecnologia Social - que envolvia pesquisadores, professores e pessoas diversas engajadas na temática, assim como grupos e redes variados, tais como Rede de Extensão Tecnológica Popular (RETEP) e a Rede de Engenharia Popular Oswaldo Sevá - REPOS — originou-se um grupo menor com inquietações mais específicas relacionadas à uma possível Associação de Tecnologia Social. Esse grupo estava especialmente interessado em aprofundar o debate sobre a Tecnologia Social, especialmente em termos de marco teórico, conceituação e relações com políticas públicas.

Os integrantes desse grupo entenderam que um caminho para melhorar os posicionamentos, os conceitos etc., seria construir uma associação, uma rede ou uma organização em volta do tema Tecnologia Social. Redigiu-se, assim, uma carta inicial, publicizada para o máximo de pessoas envolvidas com a questão; é a partir desse documento que teve início a construção da Associação Brasileira de Ensino, Pesquisa e Extensão em Tecnologias Sociais - ABEPETS, cujo nome, todavia, permanece provisório. Desde o segundo semestre de 2020, o processo vem ganhando contornos mais concretos, por meio da mobilização de pessoas do país todo e da realização de encontros e reuniões periódicas de forma on-line.

\footnotetext{
${ }^{5}$ Trata-se da Chamada CNPq/MCTIC/MDS n ${ }^{\circ}$. 36/2018 - TECNOLOGIA SOCIAL, para a qual foram enviadas
} 609 propostas, tendo sido aprovados 60 projetos, com um valor total de cerca de $\mathrm{R} \$ 5$ milhões investidos. 


\section{Podemos reconhecer as Tecnologias Sociais como algum tipo de inovação no campo das tecnologias? Quais são os elementos comuns e as divergências que podemos identificar entre tecnologias sociais e tecnologias tradicionais abordadas nas engenharias?}

$\mathrm{Na}$ verdade, a tecnologia social não está presente apenas dentro das engenharias. Talvez o fenômeno da associação apresente uma participação mais expressiva de engenheiros, mas a tecnologia social em si não está somente nessa área; não podemos restringi-la apenas à engenharia, pois existem diversos profissionais de outras áreas do conhecimento trabalhando com T.S. É importante ressaltar a presença, na Tecnologia Social, da interdisciplinaridade e da multidisciplinaridade; por mais que o grupo inicial da ABEPETS seja composto por muitos engenheiros, esse debate está longe de ser limitado a essa área.

Enfim, a tecnologia social tem algumas características bem diferentes das tecnologias convencionais - embora estas possam até chegar ao mesmo objetivo daquelas —; elas se diferenciam muito pela construção do processo. Porque o objetivo da tecnologia social é constituir um processo de produção de tecnologia participativo, enquanto as tecnologias convencionais não trabalham com essa perspectiva. Pelo contrário, normalmente as tecnologias convencionais são processos mais alienantes e acabam limitando as pessoas a uma preocupação em relação ao uso, sem considerar as consequências ou a construção da tecnologia. Já a tecnologia social surgiu como uma alternativa, para que se tenha um processo de construção de tecnologias que apresentem resultados em termos de impacto no bem-estar social das pessoas que farão uso; mas a partir de uma construção participativa especialmente não alienante, em que as pessoas entendam todos os contextos e fatores que estão implicados na construção e no uso daquela tecnologia.

\section{Então podemos afirmar que as tecnologias sociais tem um caráter político?}

Tudo tem um caráter político, mas, para todos que trabalham com Tecnologia Social, fica mais evidente o conceito da não neutralidade da tecnologia; algo que às vezes, as pessoas que atuam com perspectivas técnicas e tecnicistas não colocam em destaque. Para nós, é muito claro que as tecnologias não são neutras e que qualquer decisão tecnológica não é absolutamente técnica; por trás, elas apresentam um aspecto político-ideológico no que diz respeito às consequências do uso e da construção dessa tecnologia. 
Nesse sentido, as tecnologias sociais assim como as convencionais possuem aspectos político-ideológicos. Pois as tecnologias convencionais tendem e querem ser vendidas como técnicas, mas nós sabemos que elas apresentam consequências político-ideológicas tanto quanto as tecnologias sociais; porém, elas não reconhecem esse processo e essa condição. Na construção do processo da Tecnologia Social, reconhecemos que o desenvolvimento da tecnologia assim como seu uso não são neutros, pois há consequências sociais em cada escolha metodológica e tecnológica.

\section{De que forma a Tecnologia Social pode contribuir com a educação superior, especialmente no que diz respeito aos cursos de formação em engenharias entre outros com forte viés tecnológico?}

A educação perpassa todos os aspectos da Tecnologia Social porque propõe uma construção participativa, o que, entre outras coisas, combate os processos que são alienantes e meramente tecnicistas. Então, durante todo processo da construção da Tecnologia Social, a educação está presente.

Em relação aos processos de formação, principalmente nos cursos superiores, a preparação para o mercado de trabalho é uma realidade e um dos focos da associação é trazer outro debate para dentro da academia, com enfoque na não neutralidade da tecnologia, o que muitas vezes é deixado de lado. Apesar de alguns cursos inserirem, em suas estruturas curriculares, disciplinas de "Ciências, tecnologia e sociedade", isso é ainda muito incipiente e ineficaz em relação à profundidade necessária para esse debate. É essa importância que a ABEPETS quer promover no que diz respeito à temática da Tecnologia Social.

Agora, não podemos deixar de entender que os estudantes têm suas vidas e que a dinâmica do capital está e estará presente. Assim, após sua formação, eles geralmente procurarão empregos em organizações que trabalham com tecnologias convencionais. Eu acredito que o processo de formação deve fazer com que esses profissionais cheguem a essas empresas cientes do que é a tecnologia convencional e de que ela apresenta consequências sociais em cada decisão técnica que é tomada. Independentemente de o profissional trabalhar em uma organização que visa o lucro e utilize tecnologias convencionais, o que queremos evitar é que a pessoa chegue ali sem a ciência e a reflexão de que aquele papel que será por ela desempenhado envolverá a tomada de decisões com consequências sociais e ambientais. 
Portanto, um dos objetivos é contribuir para que os estudantes tenham uma formação honesta e conheçam as responsabilidades da sua profissão. Essa é uma meta importante dentro de uma lógica em que sabemos que muitos egressos trabalharão com tecnologias convencionais, mas que essa atuação pode ser equilibrada com uma reflexão oriunda da Tecnologia Social. Por mais que seja um debate complexo, acredito que a associação pode fazer essa interlocução por meio dos projetos pedagógicos dos cursos, das associações de educação e dos conselhos profissionais por exemplo.

\section{Na sua análise, as ações extensionistas têm contribuído ou apresentam potencial para contribuir no enriquecimento das Tecnologias Sociais?}

Eu acredito que a maioria das ações extensionistas contribuem ou apresentam potencial para contribuir no desenvolvimento das tecnologias sociais. O processo de curricularização da extensão ${ }^{6}$ - embora possa produzir resultados muito divergentes - é uma oportunidade de construção de formações que pensem mais nas tecnologias sociais. Além disso, a dimensão extensionista já se encontra no bojo do processo de construção da ABEPETS, não é à toa que a noção de "extensão" está presente nesse primeiro nome proposto: Associação Brasileira de Ensino, Pesquisa e Extensão em Tecnologias Sociais. Nesse sentido, pensamos que, embora esse debate seja também acadêmico, ele não é unicamente acadêmico, mas abrange vários aspectos das relações com políticas públicas, movimentos sociais etc. Sendo assim, as ações extensionistas tem um papel muito importante no sentido de contribuir com uma formação que enxergue o papel dos indivíduos da sociedade na construção de tecnologias sociais.

\section{Quais seriam os principais atores no processo de desenvolvimento das Tecnologias Sociais?}

É complexo definir quais são os atores principais, tendo em vista que todos apresentam um papel e podem contribuir de maneira sinérgica na construção da Tecnologia Social. Além disso, é importante ressaltar tanto o papel da academia quanto o papel dos movimentos sociais, dos grupos comunitários, como os quilombolas, que desenvolvem a tecnologia

\footnotetext{
${ }^{6}$ A chamada "curricularização da extensão", ou creditação curricular da extensão, visa a adequação dos Projetos Pedagógicos de Curso (PPC), a fim de garantir uma porcentagem mínima da carga horária dos cursos destinada às atividades de extensão. Está prevista no Plano Nacional de Educação (PNE) e foi regulamentada pela Resolução no 7 MEC/CNE/CES, de 18 de dezembro de 2018.
} 
específica para suas necessidades. Ou seja, o protagonismo é de quem produz a tecnologia de uma forma participativa com foco na resolução de problemas sociais de pequenos, médios ou grandes grupos.

\section{Além das Engenharias, quais campos de formação podem contribuir para o desenvolvimento das Tecnologias Sociais?}

O grupo que está se reunindo para a construção da ABEPETS conta com profissionais de áreas muito diversas, como, por exemplo, oceanografia, terapia ocupacional, economia, psicologia, saúde, administração, contabilidade. Trata-se de um conjunto muito diversificado e longe de ser limitado apenas às engenharias ou às áreas chamadas técnicas. A construção da Tecnologia Social, para ser um processo participativo, requer a multidisciplinaridade, isto é, a participação de diversas áreas em uma produção de tecnologias que seja participativa, não alienante e que tenha um viés de solução de problemas sociais.

\section{Como a Associação Brasileira de Ensino, Pesquisa e Extensão em Tecnologias Sociais}

\section{- ABEPETS pretende construir um diálogo com a sociedade civil organizada?}

Na verdade, já existem algumas pessoas, dentro desse processo de organização da ABEPETS, que não fazem parte do mundo acadêmico. Além disso, é preciso pensar em estruturas de comunicação, de debate, de políticas públicas, de interlocução com governos e com movimentos sociais. Para exemplificar, existe uma ideia, ainda um pouco embrionária, de criação de um conselho não acadêmico dentro da estrutura organizacional da ABEPETS. Essa é uma possibilidade entre as propostas que vem surgindo nos debates que temos realizado e que ainda estão sendo pensadas.

Temos considerado também outras possibilidades para a inclusão da sociedade civil. Isso poderá ser efetivado por meio da participação em eventos abertos à comunidade como um todo, assim como pela construção de políticas-públicas por meio de propostas apresentadas aos entes governamentais. Essas são algumas das alternativas para alcançar outro público além daqueles oriundos das universidades e das instituições de ensino e pesquisa em geral. 


\section{Em uma sociedade em que o desenvolvimento tecnológico está hegemonicamente vinculado aos interesses do capital, como é possível fazer da tecnologia um instrumento de emancipação das classes populares?}

As tecnologias sociais são produções que podem ser consideradas como bottom-up, de baixo para cima, uma vez que propõem uma construção mais coletiva, mais participativa. Elas têm por objetivo promover a emancipação de grupos sociais em relação à dependência da tecnologia convencional, que normalmente é explorada pelo capital em termos de lucro. Obviamente, não se trata de abandonar o uso das tecnologias convencionais; mas, quando se produz tecnologia social, desenvolve-se também uma outra perspectiva de utilização e de construção. E é exatamente esse o nosso objetivo: fazer com que os indivíduos consigam, em algum grau, essa emancipação em relação à dependência da tecnologia convencional capitalista cuja finalidade é lucrar.

Por outro lado, ainda é um desafio a inclusão de pessoas de fora da esfera acadêmica no processo de construção da ABEPETS. Reconhecemos que a iniciativa da associação parte de um grupo que está, majoritariamente, vinculado a alguma instituição de ensino e pesquisa e, apesar de hoje contarmos com pessoas que não fazem parte desse meio, elas ainda são uma minoria. Então, apesar da dinâmica de constituição da associação ter se originado no campo acadêmico, nós conseguimos alcançar algumas pessoas de outros setores da sociedade por meio da carta inicial que redigimos para publicizar o convite à formação da ABEPETS. À medida que a associação está sendo construída, nós queremos ampliar esse debate.

Agora, a associação também possui uma finalidade acadêmica. $\mathrm{Na}$ verdade, ela tem o intuito de posicionar o campo de estudos da Tecnologia Social; e tem um objetivo político de posicionar esse campo diante de outros campos de estudos; assim como de se colocar frente à estruturação de políticas públicas que venham a ser implantadas pelo Estado.

E quanto ao desafio de trazer pessoas de fora da academia para o processo de construção da associação, há dois aspectos diferentes a serem considerados. Uma questão é a produção de tecnologias sociais; outra, é a constituição da ABEPETS. Independentemente do desafio em relação a esta última, nada impede que as construções das tecnologias sociais sejam mais participativas. E esse aspecto tem sido buscado constantemente por todos que trabalham com Tecnologia Social e que têm feito parte da elaboração da associação. 


\section{As Tecnologias Socias podem se materializar em que tipo de intervenção?}

Independentemente de qual categoria de tecnologia estamos abordando, convencional ou social, e apesar de, no senso comum, a palavra tecnologia remeter, na maioria das vezes, ao uso da tecnologia da informação, ela é, na verdade, um meio de se organizar um processo a partir do conhecimento que temos do contexto em que ele se insere. Essa é uma conceituação diferente de tecnologia; mas, em geral, temos definições diversas segundo sua aplicabilidade.

As tecnologias sociais também podem utilizar a internet entre outros fatores relacionados à tecnologia da informação, como, por exemplo, sites colaborativos de venda, sistemas colaborativos de gestão da qualidade em cooperativas; ou podem também ser sistemas mais mecânicos, como moinhos que fazem beneficiamento de produtos agrícolas; ou máquinas de produtos agrícolas produzidas colaborativamente. A T.S. pode também dizer respeito a tecnologias de processos, intervindo diretamente na organização da produção de maneira mais participativa e que, ao mesmo tempo, promova uma melhoria do trabalho e do bem-estar coletivo.

O campo das T.S. se propõe a pensar alternativas tecnológicas que se mostrem mais sustentáveis e ecológicas. Como conciliar essa perspectiva com o estabelecimento de parcerias com empresas e grandes companhias que, em sua atuação, frequentemente se mostram extremamente negligentes e maléficas do ponto de vista ambiental?

A questão é bastante complexa, mas acredito que a associação também tem esse papel. Talvez essa seja uma das principais motivações para agrupar essas pessoas em torno de uma organização, já que acreditamos na força da rede de colaboração. Nesse sentido, acreditamos que a viabilização de projetos com características sustentáveis e de desenvolvimento de tecnologias sociais, sem a dependência do capital, tem de vir do financiamento público. E a organização tem uma maior capacidade de desempenhar um papel de interlocução com as entidades públicas, com os órgãos de fomento de pesquisa e de extensão, com ministérios etc. Nós sabemos que, na medida em que vamos produzindo pesquisa dependendo do capital privado, vai se tornando, cada vez mais difícil, desenvolver os trabalhos de forma independente. A ABEPETS pode contribuir no fomento de um debate que questione as consequências dessa condição de dependência do capital privado. 
Esse também é um debate que as universidades devem fazer dentro dos seus órgãos colegiados. É necessário refletir sobre o quanto essas instituições querem ou não a interferência das empresas privadas. Essa é uma discussão um tanto quanto difícil porque há posições muito divergentes dentro das próprias comunidades acadêmicas, em função dos interesses distintos que mobilizam pesquisadores, empresas, estudantes etc. Por exemplo, alguns estudantes podem questionar ou até mesmo não se conformar com o fato de a instituição não estabelecer parcerias com determinada empresa, na qual o próprio graduando visa trabalhar futuramente, porque essa empresa exige que as pesquisas sejam limitadas ao seu próprio benefício e nós não gostaríamos que as universidades tivessem esse papel.

\section{Na sua opinião, quais são os maiores desafios para o desenvolvimento da ABEPETS?}

Os desafios são muitos e em várias frentes diferentes. Há o desafio da aproximação com a comunidade fora da academia; o de manter a estruturação da organização, porque são trabalhos voluntários; o de conseguir definir os conceitos devido a serem muitas correntes e vertentes distintas entendidas por diferentes pessoas; e depois há o desafio da própria atuação da associação, no sentido de ela se mostrar capaz de construir respostas para as questões que ela se propõe a enfrentar. Assim, a ABEPETS buscará o desenvolvimento de tecnologias sociais, a articulação com políticas públicas, a consolidação da T.S. enquanto campo acadêmico, assim como a aproximação em relação aos movimentos sociais. Trata-se de uma série de desafios que não são pequenos, mas temos ciência de que se trata de um processo de longo prazo. 